\title{
Exploring Reflective Capacity among First-Year Students on a Computer in Education Course
}

\author{
Fariza Khalid1, Siti Fatimah Mohd Yassin², Md Yusoff Daud1, Aidah Abdul Karim1, \\ Mohd Jasmy Abd Rahman 1 \\ ${ }^{1}$ Department of Teaching \& Learning Innovations, Faculty of Education, National University of Malaysia, \\ Bangi, Malaysia \\ ${ }^{2}$ Department of Educational Leadership \& Policy, Faculty of Education, National University of Malaysia, \\ Bangi, Malaysia \\ Email: fariza.khalid@ukm.edu.my, sfmy@ukm.edu.my,mdyusoffdaud@ukm.edu.my, eda@ukm.edu.my, \\ mjas@ukm.edu.my
}

Received 3 November 2015; accepted 22 January 2016; published 25 January 2016

Copyright (C) 2016 by authors and Scientific Research Publishing Inc.

This work is licensed under the Creative Commons Attribution International License (CC BY).

http://creativecommons.org/licenses/by/4.0/

(c) (i) Open Access

\section{Abstract}

Reflective thinking requires higher order thinking skills as it involves students' capacity to think, react and decide rationally. Thus, it is important for students to master reflective thinking skills as this will help to improve their learning outcomes. In the Computer in Education course, students are exposed with new skills related to current technologies, and are promoted to apply the technologies for teaching and learning purposes. All these skills are gathered through learning by doing process during the class which requires students to actively apply their reflective thinking. This study was conducted to identify reflective thinking capacity among the overall 123 first year students who took this course. Data were collected through an online questionnaire, composed using the Google Forms. An analysis was conducted using SPSS version 22 to produce descriptive as well as inferential analysis. The results indicated that students showed a high mean in the aspects of reflective thinking- "reflection" and "critical reflection" which indirectly indicated their ability to critically reflect on the processes they did and how to improve the processes. The findings also indicated that students showed an agreement with the fact that what they did previously and the course had challenged some of their firmly held ideas.

\section{Keywords}

Reflective Thinking, Learning, Computer Education, Analysis, University Students 


\section{Introduction}

The Computer in Education (GE1155) is a compulsory course for all first-year students in the Faculty of Education, Universiti Kebangsaan Malaysia (UKM). This course aims to prepare pre-service teachers with knowledge and skills related to using computers for teaching and learning, research, and management; i.e. it is related to computers as a "tool", "tutor" and "tutee". This course also introduces issues related to twenty-first century skills, Web 2.0, Microsoft Office, OpenOffice.org and other open source software, and the use of social media as a learning platform.

The topics offered on the course require students not only to practice new skills, but also to create meaning and construct their own conclusions based on their learning-by-doing experiences regarding all the related topics. In addition, collaborative work is an essential part of the learning activities, which is called the "Think, Pair and Share" process. This strategy is designed to differentiate instruction by providing students with the time and structure to think about a given topic, enabling them to formulate individual ideas and share these ideas with a peer. This learning strategy promotes classroom participation by encouraging a high degree of pupil response, rather than using a basic recitation method in which a teacher poses a question and one student offers a response. This means that the role of lecturers is no longer solely as an information provider. Rather, lecturers are functioning as facilitators to support students' learning. On this course, students are also highly encouraged to actively engage themselves in online discussions using the Weebly platform as shown in Figure 1. In this platform, students and lecturers can create new topics for discussion, and all students are able to read and give their feedback whenever they wish, as this platform uses asynchronous communication.

Weebly is an online application that allows users to design and develop a website, blog and forum to interact for free without using any HTML code. Among the main techniques used to edit pages on Weebly is the concept of drag-and-drop, as well as various other techniques. This makes Weebly preferred by more than 20 million registered users (Weebly, 2015). In addition, Weebly operates in eleven major languages, and it can be used effectively not only on laptops, but also on tablets and smartphones. Like other hosts, Weebly provides a variety of attractive designs to suit its target users. Using Weebly, users especially educators can create classrooms to manage a large number of students as shown in Figure 2.

Weebly is used as a platform for developing the course website for the Computer in Education course, it is also used for students to create their own e-portfolios. The e-portfolio enables students not only to explore new Web 2.0 applications but also be able to showcase their work. In their e-portfolios, as shown in one of the examples of students' e-portfolio in Figure 3, students are asked to create at least three pages, i.e. "About Me" (an introduction to themselves and their background), "My Reflections" (in which students are required to write down their reflections on their weekly activities in the GE1155 course) and "My Assignments" (in which students share

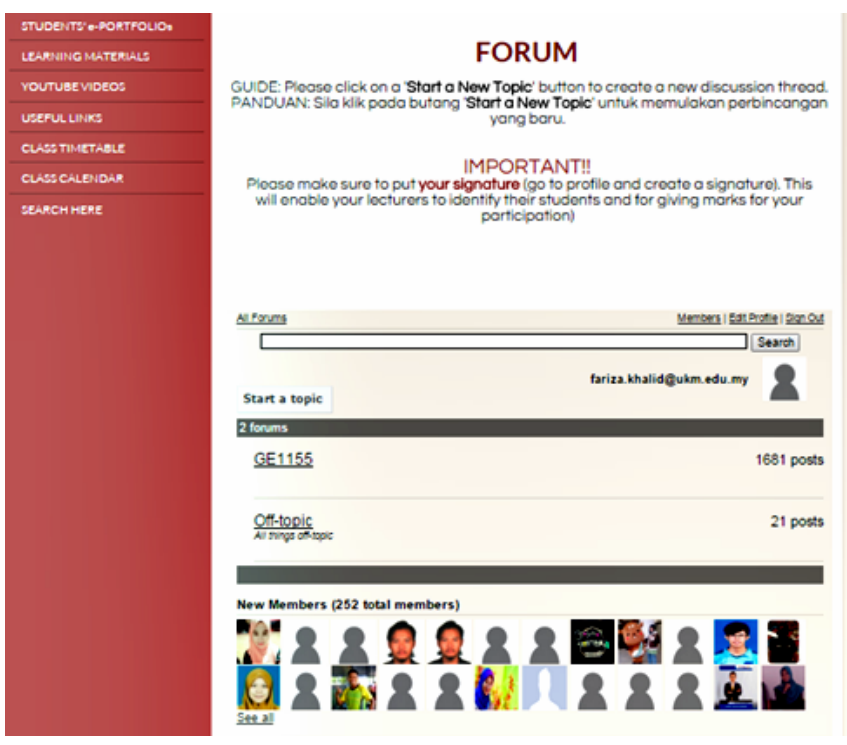

Figure 1. Forum space in Weebly, GE1155’s website. 


\section{Student Website Accounts}

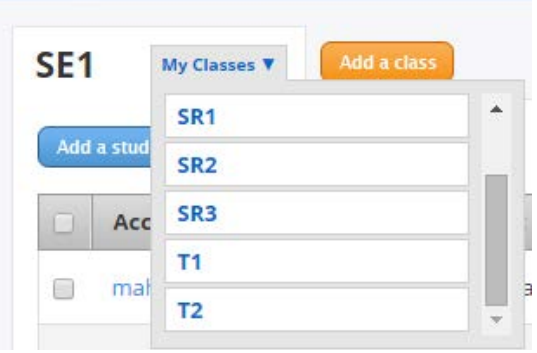

Figure 2. “Classes” created using Weebly.

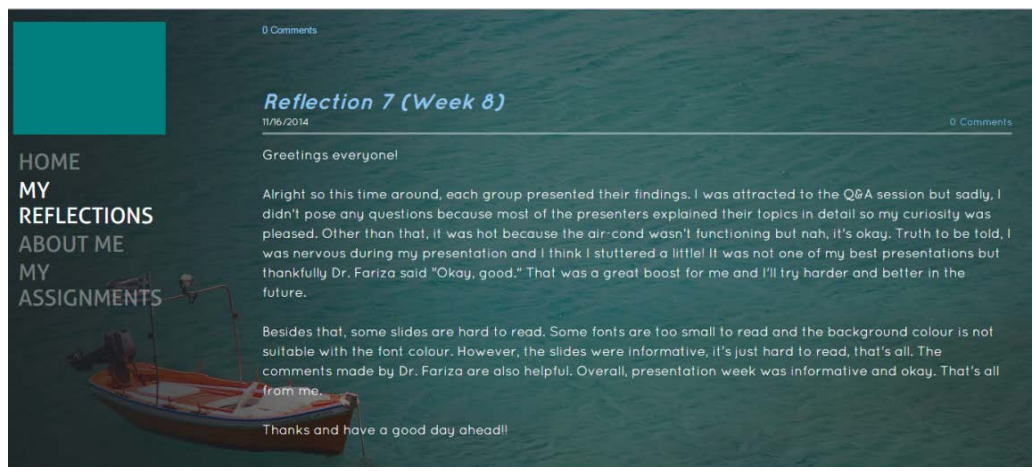

Figure 3. An example of a student's reflection.

all the assignments they produce during the 14 weeks of the semester). Using Weebly, lecturers are able to monitor their students' e-portfolio progress or to check on their assignments and reflections on a regular basis, as Weebly allows users to create classes. Weebly also allows lecturers to provide each student with a username and a default password before they start their e-portfolios.

\subsection{E-Portfolios}

Portfolios have recently become one of the most discussed innovations in higher education. A portfolio is defined as an "organized and systematic compilation of the various achievements which document the inherent professional advancement, objectives, efforts, attitudes, pedagogical practices, achievements and talents, and growth through periods; a process based on production and construction steps, where educators must do through intellectual thought, for the selection and collection of multiple sources of knowledge” (Awwad, Nofal, \& Salti, 2013: p. 79). An electronic portfolio, or e-portfolio, is a digitised version of a portfolio, which consists of the resources and accomplishments of a student. This collection can be in the form of text, graphics or multimedia, and can be archived on a CD-ROM or on a website.

Both formative and summative assessments can be done through e-portfolios. Henderson, Napan, \& Monteiro (2004) posit that e-portfolios have an impact on educational practice that can be used to document learning in progress, as well as its culmination. The creation of e-portfolios also promotes active engagement among students in organising, synthesising and describing their achievements (Bell et al., 2011). Zeichner \& Wray (2001) stress that through the use of e-portfolios, students are able to develop their thinking skills and engage themselves in collaborative works and interactions about their learning. The benefit of e-portfolios is that students are able to get access to others' e-portfolios available online, to see examples of others' work and to have discussions about their tasks.

Another important element of e-portfolios is students' reflections and self-evaluations (Lankes, 1995). Thus, an e-portfolio is not merely a compilation of students' work, but it also helps students to gain value from the process of continuous self-assessment and reflection, which involves higher-order thinking skills, and reflects students' progress, strength and creativity, as well as their capability to apply a concept or piece of knowledge they have gained through their course in their tasks (Awwad, Nofal, \& Salti, 2013). 
Implementing e-portfolios also requires planning, new procedures and new ways of thinking (Awwad, Nofal, \& Salti, 2013). One of the critical benefits of implementing an e-portfolio is that students can ensure the high quality of portfolio artifacts through their own reflection processes (Park \& Lim, 2007). Reflective thinking is a key component to support deep learning. That is why e-portfolios provide the necessary conditions for cultivating thinking among students (Chung, Leong, \& Loo, 2006).

\subsection{Reflective Thinking}

Reflective writing in e-portfolios or learning journals is widely used in higher education contexts, as the reflections can demonstrate students’ learning (Bain et al., 1999). There are many definitions of reflective thinking. For example, Boud, Keogh and Walker (1985: p. 18) state that "reflection in the context of learning is a generic term for those intellectual and affective activities in which individuals engage to explore their experiences in order to lead to new understanding and appreciations”. In order to develop reflective capacity, students should be exposed to the learning experiences that equip them with the ability to engage in reflective practices (Schon, 1987).

Kember et al. (2000) separate reflective action from non-reflective action. They identify two categories of non-reflective actions: a) habitual action, and b) understanding; and two categories of reflective actions: a) reflection, and b) critical reflection. These constructs are derived from previous work by Mezirow (1991).

According to Baxter (1992: p. 384), what is meant by "habitual action" is "that which has been learnt before and through frequent use becomes an activity that is performed automatically or with little conscious thought”. In the context of learning on the GE1155 course, it is anticipated that students will learn and be able to apply some knowledge in the production of their personal e-portfolios using Weebly. In time, this may become habitual or "taken-for-granted" (Lucas, 2011). As students become more used to the creation of entries and uploading material to their e-portfolio or writing their reflections, tasks that initially seemed ill-structured become seen as well-structured, and students do not have to think too much in completing their weekly routine tasks. Awwad, Nofal, \& Salti (2013) describe habitual action by giving an example of using a keyboard or riding a bicycle. Once a person is used to keyboards or bicycles, the tasks can easily be done. However, habitual action may differ from one student to another, as it will be determined by the extent to which they are accustomed to performing a task.

The next category is “understanding”, which Kember et al. (2000: p. 384) describe as “thoughtful action” that "makes use of existing knowledge, without attempting to appraise that knowledge, so learning remains within pre-existing meaning schemes and perspectives. Thoughtful action can be described as a cognitive process”. They also posit that "thoughtful action" or "understanding” is the best description of the phase of learning that takes place in universities. To them, Bloom’s taxonomy’s perspective of learning, which covers knowledge, comprehension, application, analysis and synthesis, would generally be placed in Mezirow's “thoughtful action” category. For example, in the GE1155 course, the use of Excel could be adopted by students to manage their monthly expenditure, in addition to managing marks in a classroom context, or the use of Weebly could be adopted for creating a business website.

"Reflection" involves the "critique of assumptions about the content or process of problem solving. The critique of premises or presuppositions pertains to problem posing as distinct from problem solving. Problem posing involves making a taken-for-granted situation problematic, raising questions regarding its validity” (Kember et al., 2000: p. 384). For example, in the GE1155 course, students might reflect on the applicability of certain video creation techniques.

The last category is “critical reflection”, which involves the critique of assumptions (Lucas, 2011). Mezirow (1991: p. 223) describes this as "transformative learning”, which involves the transformation of the beliefs, opinions, attitudes and emotional reactions that constitute students’ meaning scheme. Lucas (2011: p. 6) further explains this as involving reflection on presuppositions or "the assessment of assumptions implicit in beliefs, including beliefs about how to solve problems". For example, students on the GE1155 course might undergo a realisation that there are certain tricks or techniques that should be used instead of what they previously did. In addition, by reading others' reflections, students will gather certain ideas about how to create better reflections, which transform their current understanding of what reflection means. They may then realise that writing reflections is not solely done for the sake of writing, but it challenges their critical and reflective thinking: as Kember et al. (2000: p. 385) explain, “critical reflection” involves "becoming aware of why we perceive, think, feel or act as we do". 
On the GE1155 course, the aims are to expose students to learning experiences that equip them with reflective practices, so that they will be able to develop their reflective capacity (Schon, 1987). However, it is important for researchers to gain insights into whether the learning experiences on the GE1155 course really raised students' levels of reflective and critical thinking as anticipated. This is because simply asking students to reflect will not fully give meaning to their learning. It is vital for lecturers to have an understanding of how the students think and what kind of support can be given to enhance the students' capacity to do meaningful reflection, which will then improve their learning. This study aims to determine the extent of students' reflective skills, as having reflection skills is vital for them to be able to reflect upon their learning and thus determine the aspects to be improved in future learning tasks.

\section{Methodology}

\subsection{Research Participants}

The participants in this study were 123 first-year students (aged 19 - 20 years old) in the Faculty of Education, who enrolled in three programmes, i.e. Special Education, Sports and Recreation, and Teaching English as a Second Language (TESL). These students were taking the GE1155 course as a compulsory subject. As shown in Table 1, of these 123 students, 33 were from Teaching English as a Second Language (TESL), 48 were from Special Education, and 42 students were from Sports and Recreation.

In terms of their gender, as shown in Table 2, $65 \%$ were female students $(\mathrm{n}=80)$ and $35 \%$ were male students $(n=43)$.

\subsection{Data Collection and Analysis}

Data collection was done using an online questionnaire. The questionnaire was adapted from the questionnaire of Reflective Thinking (QRT) by Kember et al. (2000), which measures students' levels of reflective thinking. The questionnaire consisted of four constructs that assessed four levels of reflective thinking, i.e. habitual action, understanding, reflection and critical reflection. These four constructs were represented by four items, and each item was in the form of a statement using a five-point Likert Scale, ranging from Totally Disagree (Scoring 1) to Totally Agree (Scoring 5). Cronbach alpha values for these four scales are as shown in Table 3:

Table 1. Research participants based on their programs.

\begin{tabular}{ccc}
\hline Programs & $\mathrm{n}$ & $\%$ \\
\hline TESL & 33 & 27 \\
Sports and recreation & 42 & 34 \\
Special education & 48 & 39 \\
\hline
\end{tabular}

Table 2. Research participants based on their gender.

\begin{tabular}{ccc}
\hline Gender & $\mathrm{n}$ & $\%$ \\
Male & 43 & 35 \\
Female & 80 & 65 \\
\hline
\end{tabular}

Table 3. Cronbach alpha values for four scale.

\begin{tabular}{cc}
\hline Scale & Cronbach alpha \\
\hline Habitual action (HA) & 0.621 \\
Understanding (U) & 0.757 \\
Reflection (R) & 0.631 \\
Critical reflection (CR) & 0.675 \\
\hline
\end{tabular}

(Kember et al., 2000: p. 387). 
The questionnaire was developed using Google Forms, and administered during the last week of the semester, i.e. after the students had completed their assignments and reflections in their e-portfolios. The responses were derived from the Google Form and then transferred to SPSS Version 22 for analysis.

\section{Result and Discussions}

\section{Students' Reflective Capacity}

"Habitual actions” and "understanding” are described by Kember et al. (2000) as non-reflective actions, while "reflection” and “critical reflection” are reflective actions. For students' habitual actions (see Table 4), it can be seen that students, while undergoing the course, still use their habitual actions or, in other words, there are things that students do not have to think too much about to do them. This can be seen in the statement: "When I am working on some activities, I can do them without thinking about what I am doing” $(\mathrm{M}=3.17)$. It may be true that for some tasks, for example creating new entries for their e-portfolios, students were used to the steps involved as the tasks were done every week, as they agreed with the statement: "In this course we do things so many times that I have started to do them without thinking about it” $(\mathrm{M}=3.32)$. However, for the statement: “As long I can remember handout material for the examination, I do not have to think too much” $(\mathrm{M}=3.21)$, most of the students seemed unsure about the statement that they did not have to think too much to score well in their examinations, as the majority of the answers nested under $3(n=52)$. This indirectly indicates that the students were aware that the examination for this course not merely assessed their understanding and memorisation, but rather, it would involve more critical thinking skills and the application of skills gained through the course.

The next category of reflective capacity is "understanding". As indicated in Table 5, the most-selected level of agreement lay between 4 and 5, resulting in mean scores ranging from 4.00 to 4.52 . Students seemed to agree that the course required them to have an understanding of the concepts. This can be seen in the statement: "This course requires us to understand concepts taught by the lecturer” $(\mathrm{M}=4.26)$. This is also supported by the next statement: "To pass this course I need to understand the content”, which resulted in a mean score of $\mathrm{M}=4.52$. Students also revealed their agreement with the fact that being able to understand a concept, to explain it, and to discuss topics with others were essential elements in completing their tasks. This can be seen in the last two statements in this category: "I need to understand the material taught by the lecturer in order to perform practical tasks” $(\mathrm{M}=4.28)$, and "In this course I have to continually think about the material I am being taught” $(\mathrm{M}=$ 4.00).

Table 4. Students’ thinking practices governed bu habitual actions.

\begin{tabular}{|c|c|c|c|c|c|c|c|}
\hline Items & 1 & 2 & 3 & 4 & 5 & Mean & Standard deviation \\
\hline $\begin{array}{l}\text { When I am working on some activities, I can do them } \\
\text { without thinking about what I am doing }\end{array}$ & 16 & 15 & 35 & 44 & 12 & 3.17 & 1.17 \\
\hline $\begin{array}{l}\text { In this course we do things so many times that I have } \\
\text { started to do them without thinking about it }\end{array}$ & 12 & 12 & 40 & 37 & 19 & 3.32 & 1.15 \\
\hline $\begin{array}{l}\text { As long I can remember handout material for the } \\
\text { examination, I do not have to think too much }\end{array}$ & 7 & 20 & 52 & 26 & 17 & 3.21 & 1.06 \\
\hline $\begin{array}{l}\text { If I follow what the lecturer says, I do not have to } \\
\text { think too much on this course }\end{array}$ & 2 & 8 & 27 & 51 & 33 & 3.86 & 0.983 \\
\hline
\end{tabular}

Table 5. Students’ thinking practices to gain understanding.

\begin{tabular}{|c|c|c|c|c|c|c|c|}
\hline Items & 1 & 2 & 3 & 4 & 5 & Mean & Standard deviation \\
\hline $\begin{array}{l}\text { This course requires us to understand concepts taught } \\
\text { by the lecturer }\end{array}$ & 0 & 0 & 19 & 52 & 51 & 4.26 & 0.71 \\
\hline To pass this course I need to understand the content & 0 & 0 & 10 & 38 & 74 & 4.52 & 0.64 \\
\hline $\begin{array}{l}\text { I need to understand the material taught by the } \\
\text { lecturer in order to perform practical tasks }\end{array}$ & 1 & 2 & 15 & 47 & 56 & 4.28 & 0.80 \\
\hline $\begin{array}{l}\text { In this course I have to continually think about the } \\
\text { material I am being taught }\end{array}$ & 1 & 5 & 19 & 63 & 32 & 4.00 & 0.82 \\
\hline
\end{tabular}


"Reflection” is one of the categories under reflective actions (Kember et al., 2000). Students' reflective capacity to reflect on what should be improved can be seen in these statements: "I sometimes question the way others do something and try to think of a better way" $(\mathrm{M}=4.19)$ and "I like to think over what I have been doing and consider alternative ways of doing it" $(\mathrm{M}=4.24)$. In the next two statements: "I often reflect on my actions to see whether I could have improved on what I did" $(M=4.15)$ and "I often re-appraise my experience so I can learn from it and improve my next performance” $(\mathrm{M}=4.21)$ linked to students' reflections on what had been improved. Reflective capacities in this category cover students' reflections on what can be improved as well as their reflections on what has been improved. Based on the findings in Table 6, students' thinking practices governed by the elements of reflection can be seen in all statements. This should be true, as the students were keen in the completion of their e-portfolios and weekly written reflections. Perhaps the tasks given to them (e-portfolio and writing reflections) made them aware of what they had learned, what they had not yet learned, and what they wanted to learn.

The highest level of reflective thinking is "critical reflection". Based on the analysis (Table 7), it was indicated that most of the students chose levels 4 or 5 of agreement. The highest mean score was for the statement: "This course has challenged some of my firmly held ideas" $(M=4.25)$, followed by: "During this course I discovered faults in what I had previously believed to be right" $(M=4.08)$. The lowest mean score was for the statement: "As a result of this course I have changed the way I look at myself" $(M=4.03)$. These findings show that the students seem to agree that the learning activities on the GE1155 course had given them different insights into the concept of computers in education and how the applications available can help teaching and learning activities. The use of e-portfolios and the writing of the students' reflections gave opportunities for them to explore more of their capabilities, which had perhaps not been given in their previous learning experiences.

We also analyzed the overall mean scores for each category. As shown in Table 8, the "understanding" category produced the highest mean score $(M=4.26)$, followed by "reflection" $(M=4.19)$ and "critical reflection" $(\mathrm{M}=4.10)$. The lowest mean score was for "habitual actions". This analysis generally indicates that the GE1155 students had a tendency towards understanding and reflection, as well as towards critical reflection. It can also be seen that "habitual action" was the least used learning style among the students while taking the GE1155 course.

Table 6. Students' thinking practices governed by reflection.

\begin{tabular}{|c|c|c|c|c|c|c|c|}
\hline Items & 1 & 2 & 3 & 4 & 5 & Mean & Standard deviation \\
\hline $\begin{array}{l}\text { I sometimes question the way others do } \\
\text { something and try to think of a better way }\end{array}$ & 0 & 2 & 14 & 65 & 41 & 4.19 & 0.69 \\
\hline $\begin{array}{l}\text { I like to think over what I have been doing and } \\
\text { consider alternative ways of doing it }\end{array}$ & 0 & 2 & 15 & 56 & 47 & 4.24 & 0.73 \\
\hline $\begin{array}{l}\text { I often reflect on my actions to see whether I } \\
\text { could have improved on what I did }\end{array}$ & 0 & 2 & 18 & 61 & 40 & 4.15 & 0.72 \\
\hline $\begin{array}{l}\text { I often re-appraise my experience so I can learn } \\
\text { from it and improve my next performance }\end{array}$ & 0 & 1 & 20 & 53 & 48 & 4.21 & 0.74 \\
\hline
\end{tabular}

Table 7. Students' thinking practices to gain critical reflection.

\begin{tabular}{|c|c|c|c|c|c|c|c|}
\hline Items & 1 & 2 & 3 & 4 & 5 & Mean & Standard deviation \\
\hline $\begin{array}{l}\text { As a result of this course I have changed the } \\
\text { way I look at myself }\end{array}$ & 3 & 3 & 17 & 63 & 35 & 4.03 & 0.87 \\
\hline $\begin{array}{l}\text { This course has challenged some of my firmly } \\
\text { held ideas }\end{array}$ & 0 & 4 & 14 & 53 & 52 & 4.25 & 0.78 \\
\hline $\begin{array}{l}\text { As a result of this course I have changed my } \\
\text { normal way of doing things }\end{array}$ & 1 & 5 & 17 & 60 & 39 & 4.07 & 0.83 \\
\hline $\begin{array}{l}\text { During this course I discovered faults in what I } \\
\text { had previously believed to be right }\end{array}$ & 2 & 1 & 22 & 56 & 39 & 4.08 & 0.83 \\
\hline
\end{tabular}


Table 8. The presence of four levels of thinking among the students.

\begin{tabular}{ccccc}
\hline Mean scores & Habitual actions & Understanding & Reflection & Critical reflection \\
\hline 3.39 & 4.26 & 4.19 & 4.10 \\
\hline
\end{tabular}

\section{Conclusion}

This study has shown that learning activities on the GE1155 course promote students' reflective capacity, as is evident in the findings. The students show their agreement with the fact that they often reflect on their actions to see whether they have improved on what they did previously. The writing of weekly reflections, as well as the communication and discussions that took place on the e-forum via the GE1155 website had their merits in cultivating the way that students thought and rethought about what they have done and what is still to be done.

The findings also provide evidence of support for critical reflection on the GE1155 course, although its presence is lower than the content supporting reflection. It is evident that the students agreed with the fact that the course had challenged some of their firmly held ideas. Another set of data, i.e. their reflections on the course, revealed that most of the students had primary assumptions about the computer course. The majority of them wrote that "boring" was their first impression when they found out that the course would take place for three hours per week. However, they changed their minds after a few weeks of class. Some of them stated that the activities they went through every week "challenged their mind", "promoted collaborative work", and "required deep thinking" (related to reflective writing task), and that they were "fun” and "not just about computers" (related to their task to develop an e-portfolio to demonstrate their achievements and to promote themselves for future employment). This indirectly indicates that the GE1155 course promotes the development of reflective thinking among undergraduate students.

The findings also showed that the students seemed to have a tendency to view the course as requiring more "understanding” skills, "reflection" and “critical reflection”, rather than "habitual action". This indicates that the course requirements of GE1155 compel the students to work beyond using habitual actions in decision-making when completing their tasks in order to pass the course, as the mean score for "habitual action" happened to be the lowest among all the means.

\section{Acknowledgements}

This work was supported by [PTS-2014-009].

\section{References}

Awwad, F. M., Nofal, M. B., \& Salti, N. S. (2013). The Impact of Electronic Portfolio on Developing Reflective Thinking and Self-Directed Learning Readiness. Cypriot Journal of Educational Sciences, 8, 78-104.

Bain, J. D., Ballantyne, R., Packer, J., \& Mills, C. (1999). Using Journal Writing to Enhance Student Teachers’ Reflectivity during Field Experience Placements. Teacher and Teaching, 5, 51-73. http://dx.doi.org/10.1080/1354060990050104

Baxter, M. (1992). Knowing and Reasoning in College: Gender Related Patterns in Students' Intellectual Development. San Francisco: Jossey-Bass.

Bell, A., Kelton, J., McDonagh, N., Mladenovis, R., \& Morrison, K. (2011). A Critical Evaluation of the Usefulness of a Coding Scheme to Categorise Levels of Reflective Thinking. Assessment \& Evaluation in Higher Education, 36, 797-815. http://dx.doi.org/10.1080/02602938.2010.488795

Chung, T., Leong, M., \& Loo, J. (2006). Automated Mentoring for Reflection in an E-Portfolio. Frontiers in Artificial Intelligence and Applications, 151, 457-464.

Henderson, L., Napan, K., \& Monteiro, S. (2004). Encouraging Reflective Learning: An Online Challenge. Proceedings of the $21^{\text {st }}$ ASCILITE Conference, Perth, 5-8 December 2004, 357-364.

Kember, D., Leung, D., Jones, A., \& Loke, A. Y. (2000). Development of a Questionnaire to Measure the Level of Reflective Thinking. Assessment \& Evaluation in Higher Education, 25, 381-395. http://dx.doi.org/10.1080/713611442

Lankes, A. (1995). Electronic E-Portfolios: A New Idea in Assessment. Eric Digest. Syracuse, NY: ERIC Clearinghouse on Information and Technology, Syracuse University.

Lucas, U. (2011). Reflection: What Is Its Role in “Learning to Be a Professional”? Paper Presented at Brunel Business School, 30 November 2011. 
http://www.brunel.ac.uk/_data/assets/pdf_file/0020/145154/aarcReflectionWhatIsItsRoleIn.pdf

Mezirow, J. (1991). Transformative Dimensions of Adult Learning. San Francisco: Jossey-Bass.

Park, S., \& Lim, J. (2007). Promoting Reflective Thinking Process in Designing E-portfolios. In C. Crawford et al. (Eds.), Proceedings of Society for Information Technology and Teacher Education International Conference 2007 (pp. 164-168). Chesapeake, VA: AACE.

Schon, D. (1987). The Reflective Practitioner. London: Temple Smith.

Weebly (2015). Celebrating a Remarkable 2015! http://www.weebly.com/blog/celebrating-2015

Zeichner, K., \& Wray, S. (2001). The Teaching Portfolio in US Teacher Education Programs: What We Know and What We Need to Know. Teaching and Teacher Education, 17, 613-621. http://dx.doi.org/10.1016/S0742-051X(01)00017-8 